Thorax (1976), 31, 475.

\title{
Fibrous histiocytoma of the lung
}

\author{
J UA N L G O VIGUERA, JAVIER LOPEZ PUJOL, \\ S A N I A G DOMINGUEZ REBOIRAS, \\ JOSELARRAURI, and LUIS SCHACKE DE MIGUEL \\ Department of Thoracic Surgery, Ciudad Sanitaria de la SS 'La Paz', \\ Faculty of Medicine, University of Autonoma, Madrid, Spain
}

\begin{abstract}
Lago, J. V., Pujol, J. L., Reboiras, S. D., Larrauri, J., and Schacke de Miguel, L. (1976). Thorax, 31, 475-479. Fibrous histiocytoma of the hung. A case of asymptomatic fibrous histiocytoma of the lung is described in a 14-year-old girl. A left thoracotomy was performed followed by partial resection of the lingula. Postoperative progress was uneventful.
\end{abstract}

When a 'coin' lesion is found on radiological examination of the chest one of the differential diagnoses to be considered is fibrous histiocytoma of the lung. This lesion is difficult to classify as. its origin is not firmly established. Many authors consider it to be a variant of sclerosing haemangioma although there are no morphological criteria for such a view. The purpose of this report is to describe a case of asymptomatic fibrous histiocytoma of the lung occurring in a 14-yearold girl.

\section{CASE REPORT}

A 14-year-old white girl was referred to 'La Paz' Hospital for surgical evaluation of a pulmonary opacity found on routine $x$-ray examination of the chest. One year before admission she had complained of a mild pain in the posterior part of the left hemithorax. One month before admission she had an episode of high fever. Physical examination revealed no abnormality. Her erythrocyte sedimentation rate was $95 \mathrm{~mm}$ in the first hour but apart from this there was no haematological or biochemical abnormality. The sputum did not contain acid-fast bacilli and no tumour cells were seen. A tuberculin test was negative. Respiratory function tests were normal. The chest radiograph showed a well-circumscribed nodule $5 \mathrm{~cm}$ in diameter present in the left upper lobe (Fig. 1). A left thoracotomy was performed and a nodule was found to be present in the lingula. Partial resection of the lingula was performed. Postoperative recovery was uneventful and one year after the operation no clinical or radiological abnormality of the chest was present.
PATHOLOGY The gross appearance of the tumour showed a clearly demarcated, encapsulated nodule measuring $6 \times 5 \times 5 \mathrm{~cm}$. It was soft and the cut surface had a white fasciculated appearance punctuated by isolated yellowish areas.

Histology Sections showed the tumour to be composed of numerous spindle-shaped cells with elongated vesicular nuclei and prominent nucleoli. The cells were arranged in compact bundles with a little surrounding collagen (Figs 2 and 3). Interspersed throughout the lesion were small isolated groups of polygonal-shaped cells with plentiful cytoplasm and indented nuclei that were considered to be histiocytes. These cells were often surrounded by fairly numerous plasma cells and lymphocytes (Fig. 4).

The Prussian blue reaction revealed isolated granules of haemosiderin in some of the histiocytic zones. In other areas the histiocytes contained a considerable quantity of lipid in their cytoplasm (Fig. 5) and this was confirmed by fat stains on frozen sections.

Blood vessels were not a prominent feature of the tumour. Mitoses were very scanty and there was no significant cellular atypia. Reticulin was scanty and revealed no distinct pattern; in particular there was no evidence of its exhibiting a perivascular distribution. Scattered throughout the lesions were remnants of bronchiolar epithelium.

\section{DISCUSSION}

This type of lesion is most commonly found in women in the third or fourth decades (Liebow and Hubbell, 1956; Arean and Wheat, 1962; Mori, 


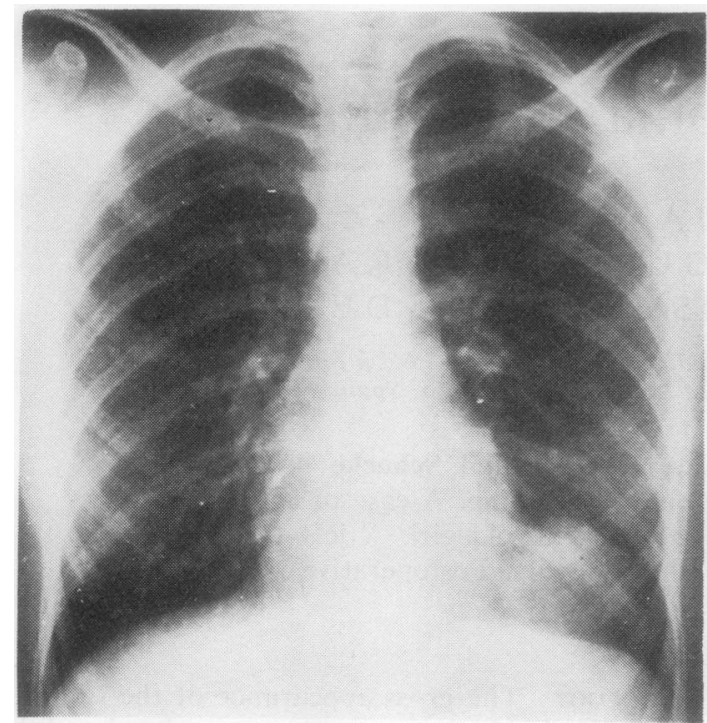

(a)

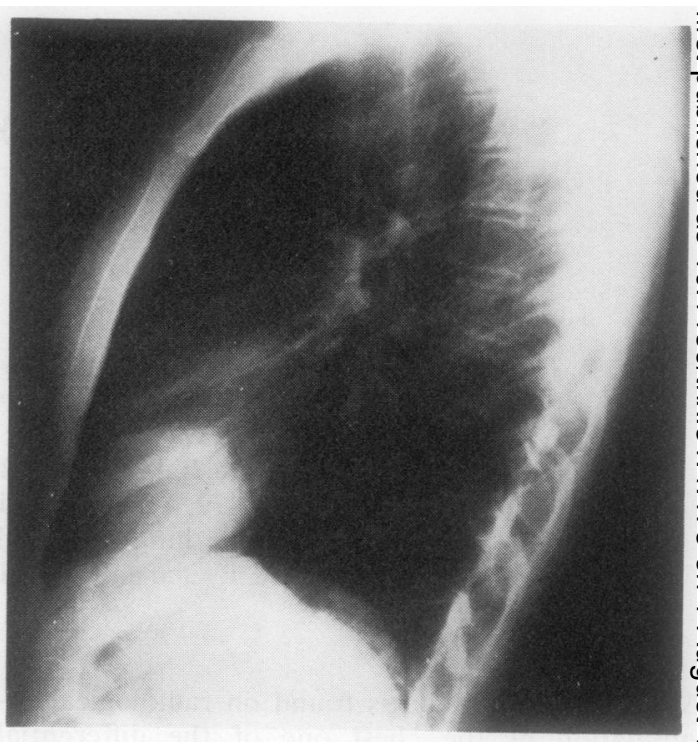

(b)

FIG. 1. (a) Chest radiograph showing lesion in left lung. (b) Left lateral chest film showing a well-circumscribed nodule located in the lingula.

1968; Haas, Yunis, and Totten, 1972; Nair, Nair, and Weisbrot, 1974). The present case is unusual in that the patient was only 14 years old. The lesion is usually asymptomatic and discovered only as a result of routine chest radiography. Occasionally there may be haemoptysis (Nair et al., 1974) or, when there is compression of the bronchial tree, dyspnoea.

The lesions are usually solitary nodules located in the peripheral regions of the upper lobes. Calcification is rarely present. Treatment does not present a problem as surgical removal is usually curative. The greatest difficulty with regard to these lesions lies in the problem of semantics. The histology shows a polymorphic response with the presence of plasma cells, lymphocytes, foamy lipid-laden histiocytes, fibroblasts with more or less collagen production, and a variable vascular component often with endothelial proliferation. The nomenclature of these lesions has been based on the relative prominence of one or more of these cellular elements. This has resulted in the lesions being referred to as pseudotumour, plasma cell granuloma, histiocytoma, xanthoma, fibrous histiocytoma, fibroxanthoma, and sclerosing angioma (Gross and Wolbach, 1943; Hill and Eggleston, 1972; Bahadori and Liebow, 1973; Ackerman and Rosai, 1974). 'This variable terminology has led to considerable confusion and has resulted in varying views on the aetiology of the lesion. Thus Areano and Wheat (1962) consider it to be a true tumouro but Sherwin, Kern, and Jones (1965) favour a $\vec{\Rightarrow}$ postinflammatory origin. There is a similarity 3 between these pulmonary lesions and cutaneous? histiocytoma (Woringer and Kviatkowski, 1932). Sézary and Lévy-Coblentz (1933) suggested that they were an intermediate form between theo histiocytoma and a true fibroma. Blood vessels are often prominent and in many instances the fibroblasts show a striking perivascular arrangement. This morphological appearance has led someô workers to use the term sclerosing haemangioma (Gross and Wolbach, 1943; Liebow and Hubbell, 윽 1956). The term fibrous histiocytoma was intro- $\rightarrow$ duced by Stout and Lattes (1967) to include all을 these lesions because they considered that in many instances the fibroblasts were derived fromhistiocytes which could show either collagen $N$ formation or a marked degree of macrophage $\underset{\omega}{ }$ activity.

More recently Spencer (1968) has suggested thateo some of these lesions may be tumours arising from $\mathbb{D}$ undifferentiated mesenchymal alveolar cells. Hill $\stackrel{?}{+}$ and Eggleston (1972), on the basis of electron 0 microscope studies, suggest that the cell of origin may be epithelial in nature whereas Haas et al. $\stackrel{\mathbb{Q}}{\stackrel{\circ}{\circ}}$ (1972) consider that the ultrastructural appear- $\mathbb{Q}$ ances favour an endothelial origin. 


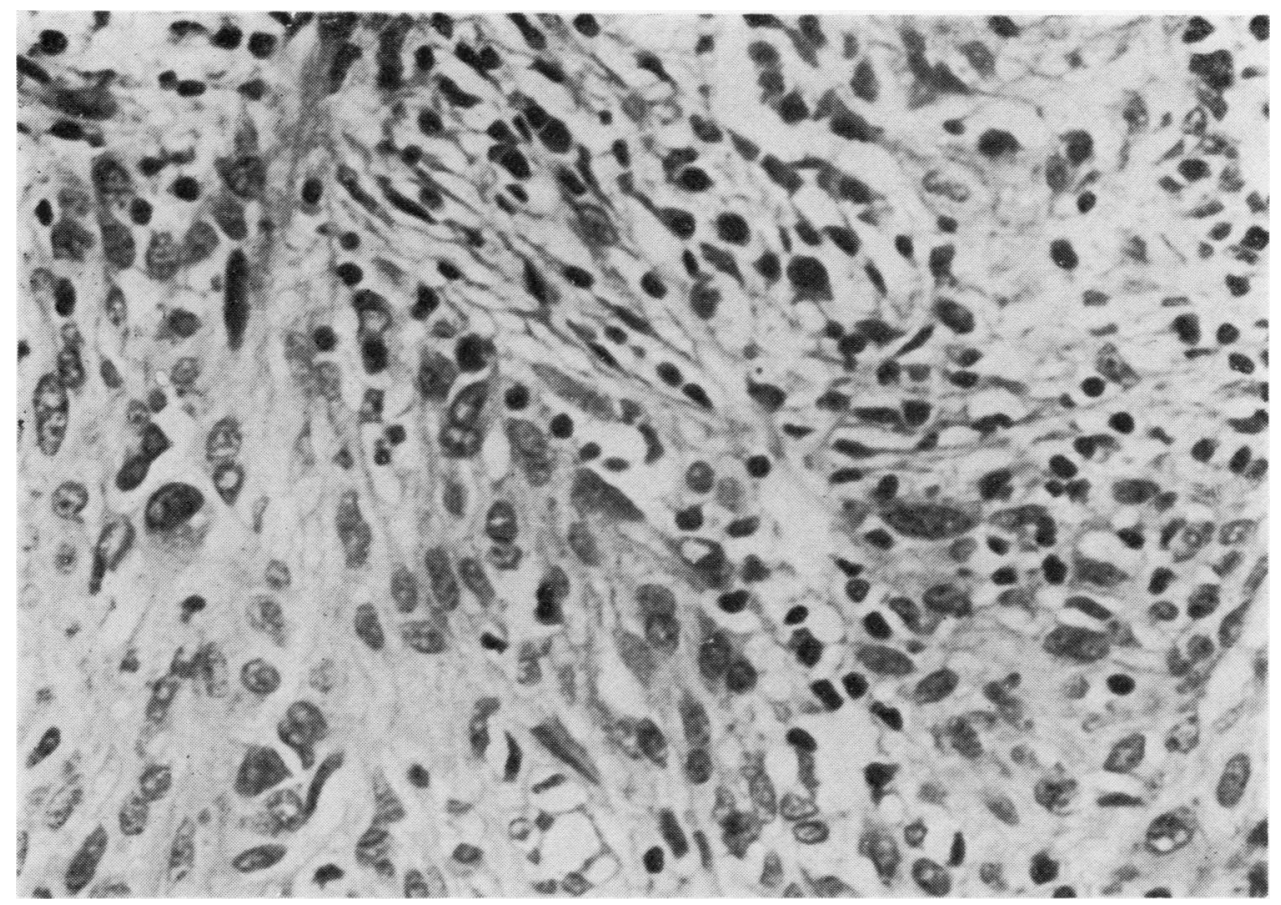

FIG. 2. Portion of the tumour composed of a highly cellular tissue, with elongated and vesicular nuclei and patent nucleoli in many ( $H$ and $E \times 96$ ).

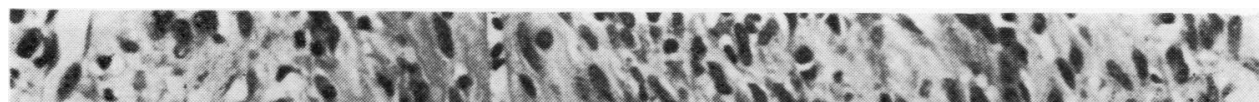
- 2. -20 -

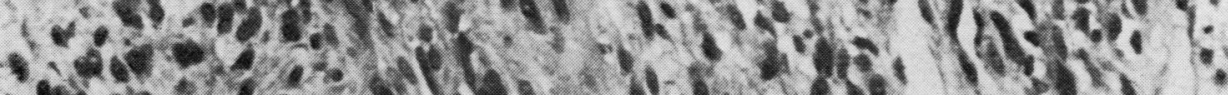
4.

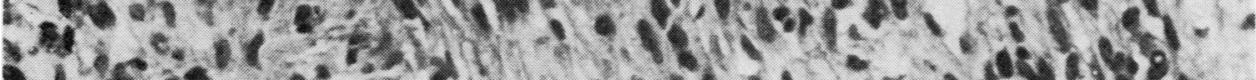

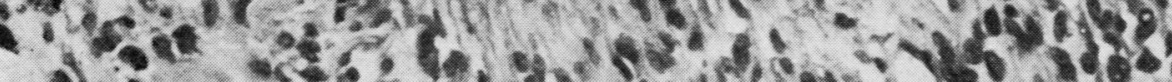

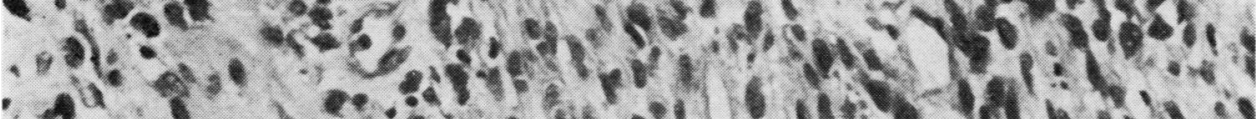

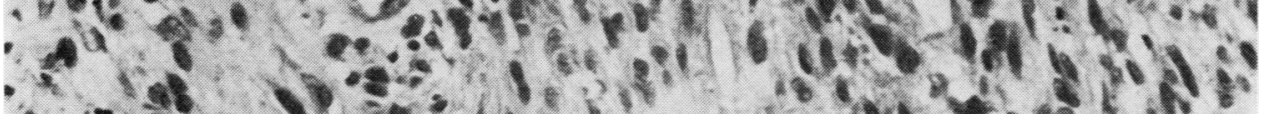

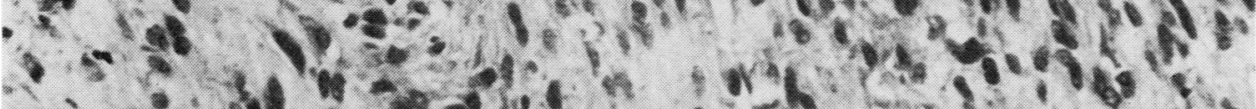

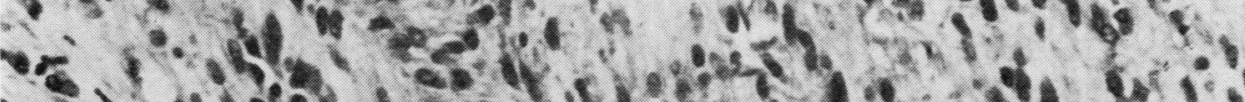

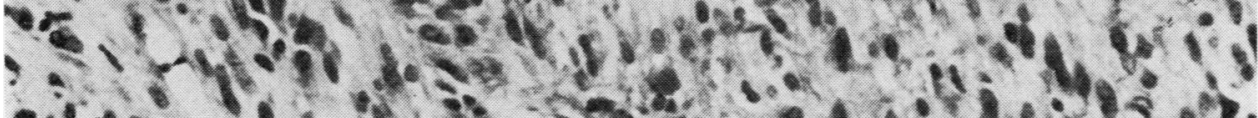

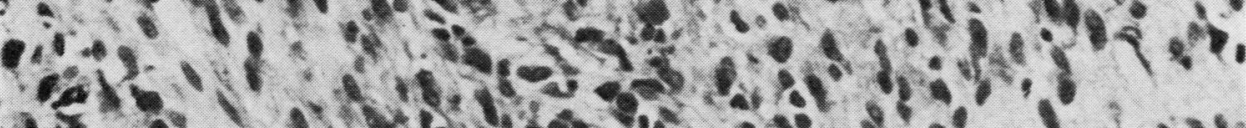

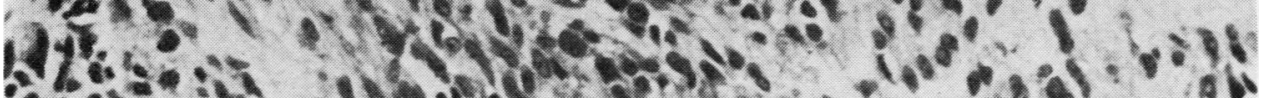
6.:

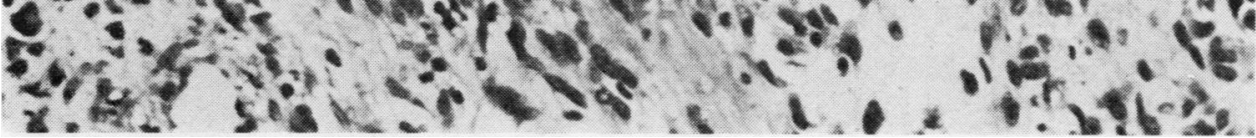

FIG. 3. Photomicrograph showing compact bundles with scattered collagen formation ( $H$ and $E \times 48)$ 


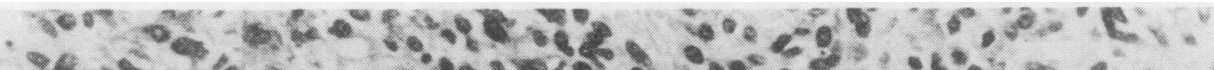

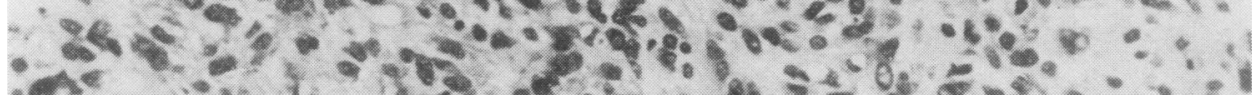

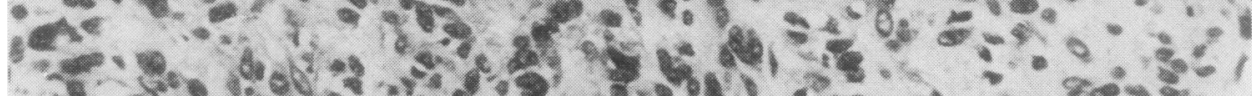

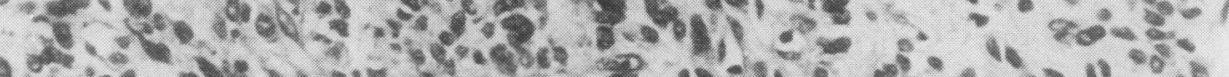

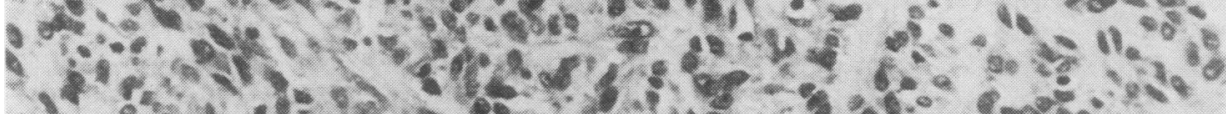

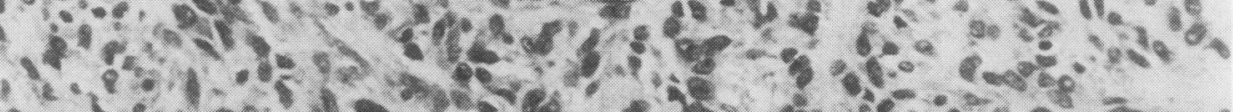

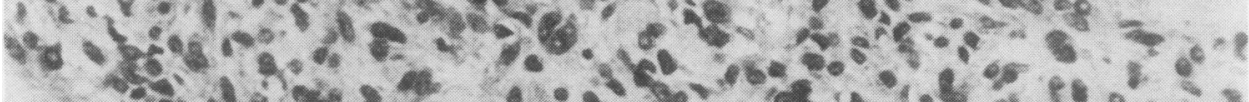

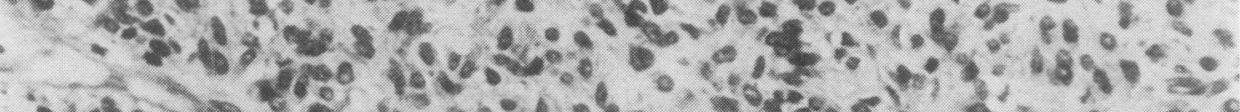

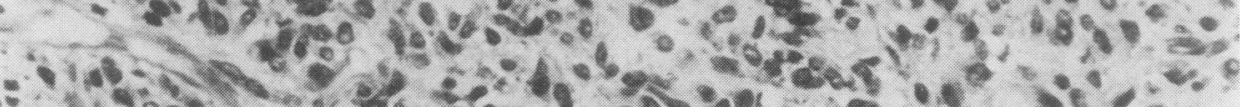

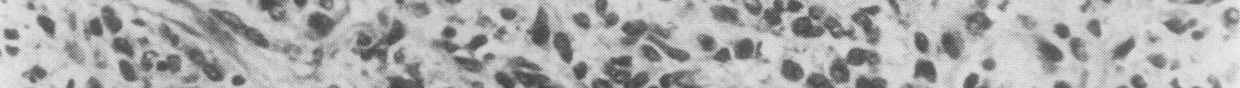

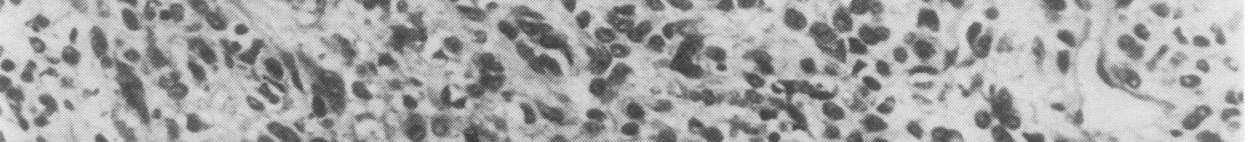

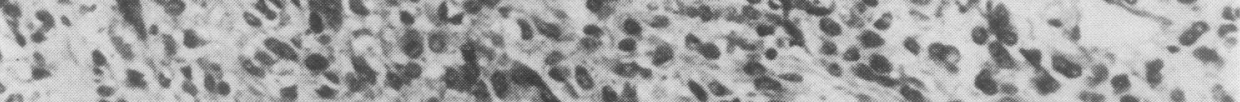

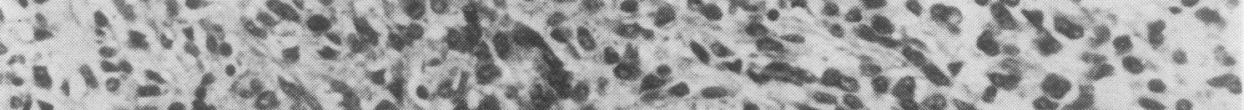
P.

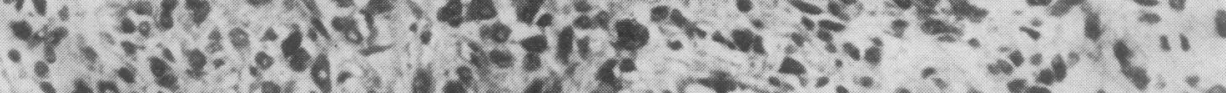
F.

FIG. 4. The histiocytes supported by numerous plasma cells and lymphocytes ( $H$ and $E \times 50)$.

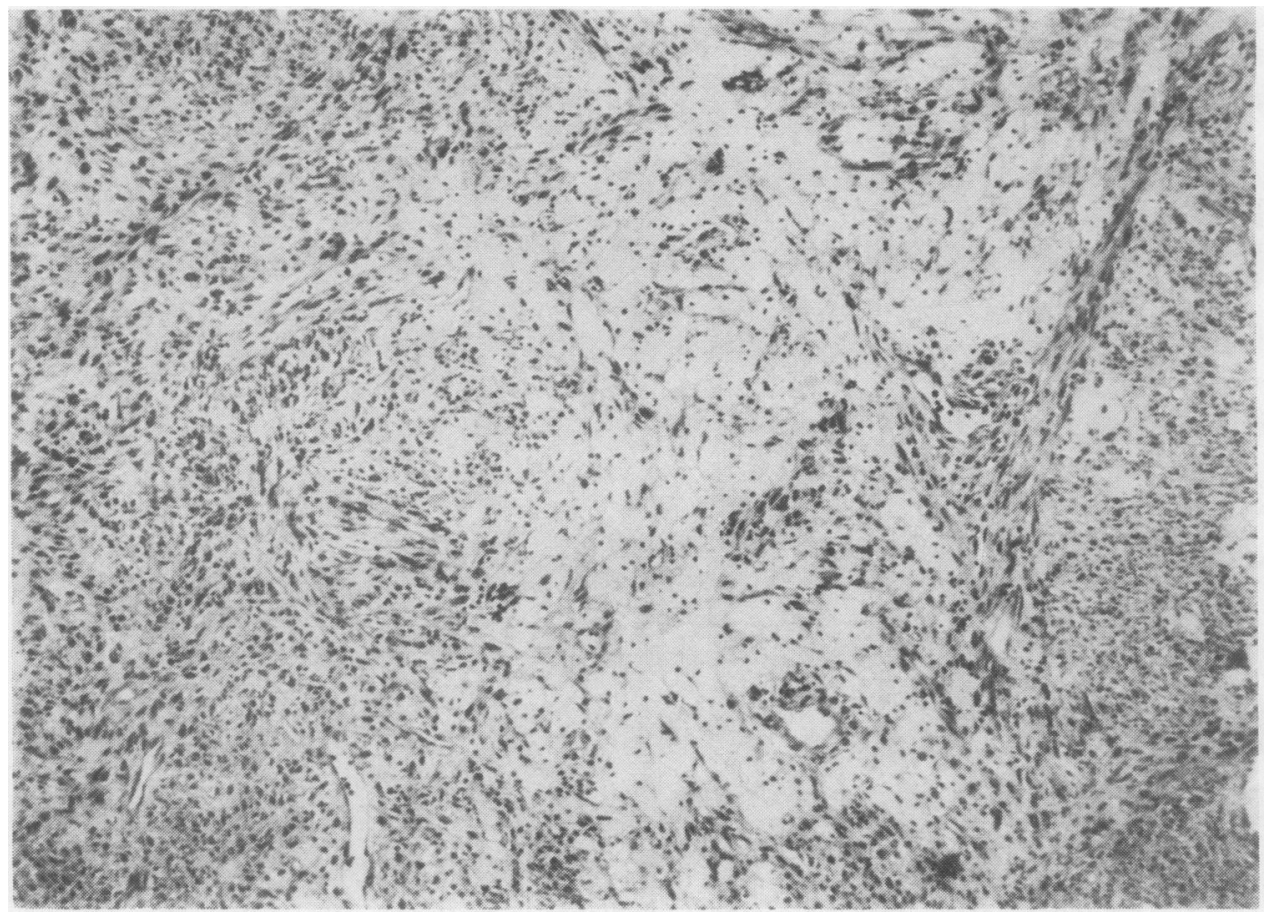

FIG. 5. Foam cells demonstrated in scattered areas $(H$ and $E \times 20)$. 
We consider that the lesion described in this case is most likely to be a reactive one and not a true tumour. The presence of histiocytes containing either lipid or haemosiderin and the absence of any true neoplastic characteristics or predominant cell type favour this hypothesis.

\section{REFERENCES}

Ackerman, L. V. and Rosai, J. (1974). Surgical Pathology, 5th edition, p. 222. C. V. Mosby, St. Louis.

Arean, V. M. and Wheat, M. W. Jr. (1962). Sclerosing hemangiomas of the lung: a case report and review of the literature. American Review of Respiratory Diseases, 85, 261.

Bahadori, M. and Liebow, A. (1973). Plasma cell granulomas of the lung. Cancer, 31, 191.

Gross, R. E. and Wolbach, S. B. (1943). Sclerosing hemangiomas: their relationship to determatofibroma, histiocytoma, xanthoma and to certain pigmented lesions of the skin. American Journal of Pathology, 19, 533.

Haas, J. E., Yunis, E. J., and Totten, A. S. (1972). Ultrastructure of a sclerosing hemangioma of the lung. Cancer, 30, 512.

Hill, G. S. and Eggleston, J. C. (1972). Electron microscopic study of so-called pulmonary sclerosing hemangioma. Cancer, 30, 1092, 1972.
Liebow, A. A. and Hubbell, D. S. (1956). Sclerosing hemangioma (histiocytoma, xanthoma) of the lung. Cancer, 9, 53.

Mori, S. (1968). Sclerosing hemangioma of the lung. Chest, 54, 381.

Nair, S., Nair, K., and Weisbrot, I. M. (1974). Fibrous histiocytoma of the lung (sclerosing hemangioma variant?). Chest, 65, 465.

Sézary, A. and Lévy-Coblentz, G. (1933). De l'histiocytome au xanthome. Bulletin de la Société Française de Dermatologie, 40, 798.

Sherwin, R. P., Kern, W. H., and Jones, J. C. (1965). Solitary mast cell granuloma (histiocytoma) of the lung. A histopathologic tissue culture and timelapse-cinematographic study. Cancer, 18, 634.

Spencer,. H. (1968). Pathology of the Lung, 2nd edition, p. 935. Pergamon Press, Oxford.

Stout, A. P. and Lattes, R. (1967). Tumors of the Soft Tissues (Atlas of Tumor Pathology, Second Series, Fascicle I.) AFIP, Washington, DC.

Woringer, M. Fr. and Kviatkowski, S. L. (1932). L'histiocytome de la peau. Annales de Dermatologie et Syphiligraphie, 3, 998.

Requests for reprints to: Dr. J. Lago Viguera, Departmento de Cirugía Torácica, Ciudad Sanitaria de la SS 'La Paz', Madrid -20, Spain. 